\title{
Education of Indonesian Girls: The Outlook of Discrimination, Rights, and the Impact on Society
}

\section{Rifka Fachrunnisa}

Department of Biology, Faculty of Mathematics and Natural Sciences, Universitas Negeri Malang, Indonesia

\section{Abstract}

The purpose of this quantitative study is to investigate the education of Indonesian girls in terms of discrimination, awareness of their rights to education, and the wider impact on society. The level of discrimination was analysed using the data of girls' educational attainment and comparing it to that of boys from low income families, obtained from the Central of Bureau Statistics (CBS) Indonesia in 2012. Awareness of rights to education was investigated using a survey with 100 participants. The result showed that in all levels of education boys had a higher level of attainment than girls.

Corresponding Author: Rifka Fachrunnisa fachrunnisa.fmipa@um.ac.id

Published: 29 July 2020

Publishing services provided by Knowledge E

(c) Rifka Fachrunnisa. This article is distributed under the terms of the Creative Commons

Attribution License, which permits unrestricted use and redistribution provided that the original author and source are credited.

Selection and Peer-review under the responsibility of the WCGS Conference Committee.
Furthermore, there are higher numbers of girls than boys in the uneducated category. Girls' educational attainment is closely linked to the human development index which is representative of society. Additionally, girls' awareness of their rights to education is still very low.

Keywords: Educational Attainment of Girls, Discrimination, Rights to Education, Human Development Index

\section{Introduction}

"As long as women are bound by poverty and as long as they are looked down upon, human rights will lack substance. As long as our cultural ways of thinking prevent women from making a meaningful contribution to society, progress will be slow"

\section{Nelson Mandela}

In most cases Indonesian girls in rural areas face the parental vision that they are ideally suited only to become a housewife, so do not need to pursue education even high school education. In order that the sight of higher educated girls in low family income still become the taboo issue. Most parents underestimate the empowerment of their daughter and place a lot of hope in their sons in term of the family's dignity. A mixed paradigm of culture and religion has influenced the parents' principles about 
rights - "Kodrat Wanita", which means the destiny of women (Pakpahan, 1996, p.10). For many parents, the important education that should be attained by girls is lessons about how to manage household properly. No matter how old the girl is, if she has been graduated from elementary school and is capable of managing household tasks, she is allowed to be married. On the other hand, boys are regarded as the backbone of family. They are responsible for fulfilling the needs of family after their parents are no longer working or retired. That is why, almost all parents attempt to give the maximum education for boys.

Another paradigm about girls' education in Indonesia is also influenced by the patriarchy system which is applied in most Indonesian provinces. This system raises the view that all the family's decisions, including financial and children's education, is managed by the man. This may lead to the exploitation of women in the household. The wife works only to maintain household tasks and fulfil the physical and psychological needs of her husband and her children. As a result, many women have to face the reality that they are intimidated by domestic violence. Eliminating women's right offences frequently happens, underpinned by the culture, and it is happening over and over again from generation to generation. It will get worse if there is no education provided to the women power to encourage them to have more voice and to have increase participation.

Because of the view that education is not a vital need for the girl, then issues arise regarding the practicality of education itself. For instance, in Indonesia there is a public opinion that education is only the school's responsibility. There is no intervention from family. Instead, in reality children spend more time in the environment outside school. This issue needs to be managed, because its effect is very detrimental especially for girls. Many factors affect girls' right in education, for example, lack of birth-control knowledge; high incidence of maternal and infant mortality; diminished food supply; loss of work; beliefs that sexual intercourse should be avoided during pregnancy and lactation; and reduced interaction because of swaddling (Hart, 1991). Although Indonesia is not the country with the highest crime rate and lowest education in the world, the main problem is that the government is still prioritising provision rather than enhancing the quality.

Education for girls has become a focus in the postcolonial era in Indonesia. This happened because of a power of the tagline "women emancipation" which is delivered by a revolution heroine named Kartini in the 1900's. This tagline has highlighted the education system in Indonesia, particularly girls' education. This impacted on education practice. Education is only for those who have high dignity and important position in the public. However, slavery is still happening until now, principally for poor families. This 
issue may be a challenge now while the country is industrialising. Most big companies choose girls as their employees for the reason that they are able to enforce the contract system, for example because of pregnancy. Also they do not have enough skill and education to get better jobs. Girls are therefore given less salary than boys (Prasilowati, 2000).

The issues that have been mentioned above such as exploitation towards girls is an abuse of human rights. This is referred to in Article 2 regarding discrimination which means there should be no differentiation in family towards the gender term in education. Therefore, this paper would attempt to investigate the discrimination in educational attainment between boys and girls, the impact of girls' education towards society and girls' awareness towards rights to education.

\section{Related Literary Review}

\subsection{Defining Discrimination}

Discrimination in this paper is defined as a condition when a woman/girl is being less well treated than a man/boy within or in connection with formal education. (McCracken et al, 2015, p.17). This discrimination has been carved in the history. Firstly, education was not open for girls until secondary education was opened for boys. Secondly, education for girls has been developed in gender-specific ways which have drawbacks in many terms. In this case, girls are excluding from particular knowledge. Thirdly, there are sexist attitudes towards girls. So that is why until now education still was seen as incompatible with the physical well-being (Paetcher, 1998, p.13). On the other side, discrimination also happened in the program of education itself. In other words, the programmes provided especially for girls tend to be designed as 'special' provision, namely programmes which diverge from the mainstream norm (McGivney, 1993, p.5).

As a developing country, Indonesia still has a big task to break the poverty line that happens in most rural areas. Regarding the poverty factor in equality, direct and indirect cost of schooling becomes a resource of the discrimination. The direct costs, such as school fees, uniforms or books, frequently become a consideration of parents to allocate expenditure for their sons rather than daughters. Additionally, indirect costs include labour that is taken away by household production (i.e. farming and trading). The employment for these core household tasks depends on girls leaving school earlier than boys (Rose and Subrahmanian, 2005). There is another financial reason that can influence girls to leave the school earlier, which is working abroad. In some of rural 
area in Indonesia are famous with the trend to work as a household assistant or nanny in middle-east countries where a lot of labour is required in those sectors. This trend is happening because many parents see the achievement of their neighbour who has success from working abroad. This excuse who make parent push their daughter to leave the school rather than their sons (Prasilowati, 2000).

Besides poverty, the power of the conditioning of school environment should be not underestimated. There are differences in teachers' approaches to boys and girls, reported by HMI (2012), these include insufficient equal opportunities measures; inadequate attention to the changing domestic and employment acts of the sexes in the school ethos, very little gender-based monitoring achievement; and little positive action to increase the expectations and widen the boundary of girls. This inequality shows the differential treatment of girls and boys by teachers and the type of omission which are hidden in many curricular (McGivney, 1993, p.22; Riddell, 1992: 49).

\subsection{Legitimacy of Equality Gender in Indonesia's Education}

Constitutionally, Indonesia gives equal access to education for the citizens. It is clearly stated in the 1945 Constitutions Article 31 that "(1) every citizen has the right to education and (2) The government shall establish and conduct a national education system which shall be regulated by law". And more specific in the Constitution No. 202003 Chapter III Article 4 states "Education held in a democratic and fair and not discriminatory by upholding human rights, religious values, cultural values, and pluralistic nation". Although the constitution seems perfect to manage the Indonesian national education system, but until recently the issues of pluralistic nation still become a huge matter. The interdisciplinary studies are needed to cope this obstacle, such as strengthening the process of monitoring and evaluation to the whole provinces in Indonesia. This is because, in terms of education, Indonesia has decentralisation principal. The educational mechanism is given to each province but it is enforced to be consistent with the Convention and/or national laws.

Apart from national constitution, the government of Indonesia also ratified the Convention on the Right of the Child through a Presidential Decree in 1990. The ratification of the Convention has inspired the amendment of Article 28B paragraph (2) of the Indonesian Constitution in 2000 "Every child shall have the rights to survival, growth, and development and shall have the rights to protection from the violence and discrimination". This Constitutional Mandate was operationally translated into Law No. 23 of 2002 regarding Child Protection (Report of the Indonesia State Party, 2007). In the 
Report (2007) also states there are several program to cope the discrimination issues. For instance, the sub-district Development Program aims to promote the livelihood of people by involving the poor, including women and children, at every stage of activities. This program has a special mechanism to accommodate the aspiration of women through Special Women Consultations, in which they can propose and be involved in every activity.

In relation to gender equality, in the Report (2007) states that Indonesia has achieved progress in decreasing gender gap in accessing primary and secondary education, as seen in the better female-to-male ratio of participation in education and level of literacy. The gender equality has been achieved at primary education level, but the ratio at the junior high school level tends to be greater than 100 per cent, which indicates greater proportion of female to male students. However, for female students in continuing to senior high school and universities still faced some challenges including practices of early marriages and a notion in the society that men are the family backbone and consequently, high education for girls is considered to be less important.

\subsection{The Role of Girls Education on The Society}

\subsubsection{The Role in the Society's Economic}

The benefit of educating a girl is spread not only for her parents but also the girl herself and her future family, as well as society at large. In Indonesian society, education is considered a value-add for females to help with the country's development (Prasilowati, 2000). Especially in market sector, there is significant evidence of benefits of educated girls in the formal labour market in the form of better employment. On the other hand, girls with higher education are generally better paid and it is easier to find employment in the paid sector than those with less education. If the girl has her own income, unless it can be transferred to their parents, she can bear some of the costs of her education. As a result, she can improve her family income (King \& Hill, 1997, p.27). The accumulation of the family who applied the same principal indirectly will increase the country's income.

\subsubsection{The Role in the Society's Health}

Some studies also noted that educating girls seems to lead to better hygiene, improved nutritional practices, and better effectiveness in caring for her family's health, so, it can reduce child mortality (Prasilowati, 2000, p.21; King \& Hill, 1997, p.28; McGivney, 1993, 
p.5). It is reasonable because educated girls gain more knowledge about health, safety risks, prevention and nutrition. The estimation is that there is a decrease of $7-9 \%$ in mortality rates for every year of a mother's education.

Subsequently, there is an increase in the health of children rates. On the other hand, educated girls impacted on the fertility rates which directly related to the control of population density. Notably, girl who has the mastery of family planning or knowledge in contraception system will be more capable of deciding the number of children in a family by considering the family's financial condition.

\subsubsection{The Role in the Society's Education}

Parents' attitudes and resources have a vigorous influence on how to determine educational attainment and outcome of their child. Every girl will become a mother, and the attitudes which is given by her parent in the past unconsciously will effect to the way she gives the attitude (expressions of autonomy) to her child including attitude towards education. In terms of sociology this is known as inter-generational effects. In reality, improving both the father's and mother's education increases the education attainment of girls than of the boys. However, raising mother's education is significantly linked to greater reduction in the difference in education attainment between girls and boys. Furthermore, there is a positive relationship between higher levels of education of the girl's and mother's expression of autonomy (McCracken, 2015, p.45). In this study, society aspect that was measured is human development index (HDI) which is represented in three dimensions: a long and healthy life, being knowledgeable and have a decent standard of living (Noorbakhsh, 1998).

\section{Methodology}

\subsection{Research Objectives}

The main objective of this inquiry is to investigate the education attainment of Indonesian girls related to the right and impact towards society which is focused on Indonesian human development index. In accordance with its objective, this study was purposed to answer these three research questions:

1. How does educational attainment between Indonesian girls and boys compare?

2. What is the correlation between education attainment of Indonesian girl and Indonesian human development index? 
3. Do Indonesian girls have awareness of rights to education?

\subsection{Study Design}

This study was conducted using quantitative method with analytical approach which employs two types of statistical data resources. Firstly, to obtain the data for educational attainment and human development index, the author took the statistical data from the Central of Bureau Statistics (CBS) Indonesia in 2012 because the data in later years is unavailable. And the data of educational attainment in this study is limited to the family which has lowest income only. On the other hand, to get data for the awareness of rights, the author used survey with 5-Likert-scale of awareness of rights to education. The five scales are: not at all aware; slightly aware; somewhat aware; moderately aware; and extremely aware. The participant of this survey included $10018-25$ years old girls who had completed primary school but did not complete their secondary school or ever attempt to take secondary school. They are surveyed using only one question about awareness of rights to education and the survey is carried out by online randomly.

\section{Result}

The data result of the study is shown in three parts. The first part demonstrates the education attainment of Indonesian girls compared with boys. Secondly, the relation between educational attainment of Indonesian girls and Indonesian human development index is explained, as the indicator for society. And lastly the awareness of Indonesian girls of rights to education are considered.

\subsection{The Comparison of Educational Attainment between Boys and Girls in Indonesia}

According to image 1, in 2012 the highest level of schooling or educational attainment between boys and girls (15-29) in the lowest income family shows that in all of the educational degree namely primary school, secondary school and higher education, boys have higher percentage than girls. In addition, girls with no education is higher than boys. Although the difference of the result is not too significant, this term has showed that there is distinction in educational intervention of parents towards the education of their daughters or sons. 


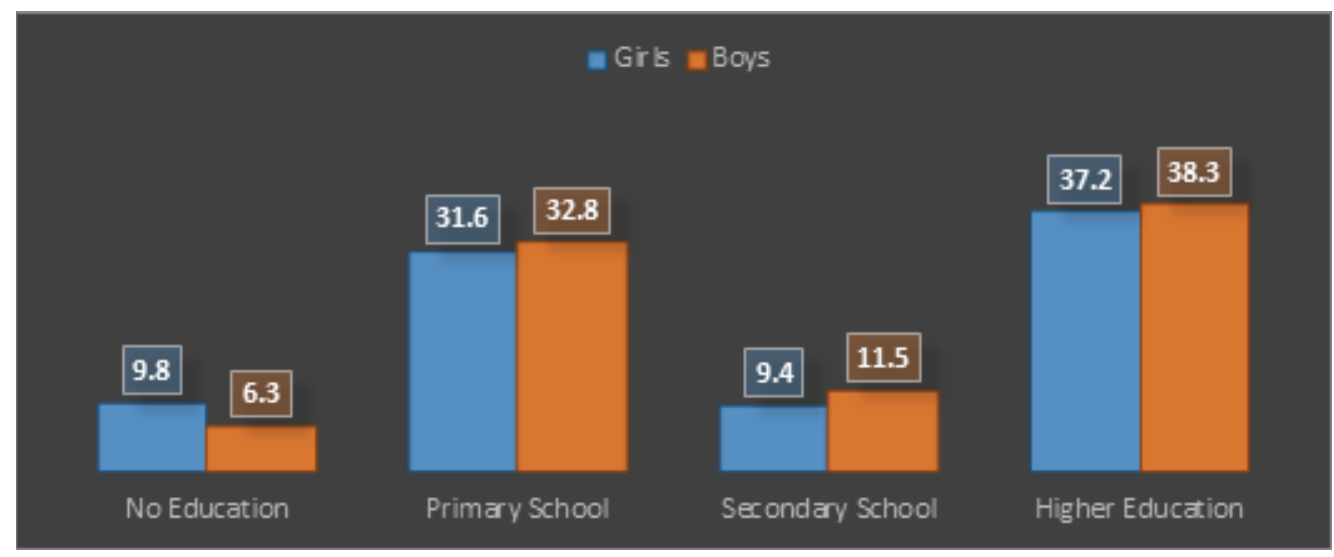

Figure 1: Educational attainment between Indonesian girls and boys in 2012

\subsection{The Relationship of Educational Attainment between Indone- sian Girls and Human Development Index}

According to previous explanation, Human Development Index (HDI) is an indication of health, education and living standard of the society. This study related the HDI data in 2012 with educational attainment of girls of 33 provinces using Spearman's rho test SPSS 20. The result (table 1) shows that all categories of educational attainment of girls has significant correlation with HDI. Mainly, secondary education has strong uphill linear relationship in both of them. This means that, until 2012, girls with highest attainment education in secondary school was the most influential factor towards Indonesian HDI. Furthermore, a positive relationship was also found in HDI vs. higher educated girls, with moderate value. Adversely, girls who have no educational attainment at all has moderate downhill linear relationship. This indicates that fewer girls with no education will add the value of HDI in Indonesia. The negative correlation is also investigated in primary educated girls vs. HDI with the moderate level.

TABLE 1: The Correlation between Educational Attainment of Indonesian Girls and Human Development Index in 2012

\begin{tabular}{l|l} 
No. & Indicators \\
$\mathbf{1}$ & No Education \\
$\mathbf{2}$ & Primary Education \\
$\mathbf{3}$ & Secondary Education \\
$\mathbf{4}$ & Higher Education \\
\hline
\end{tabular}

\begin{tabular}{|c|c|}
\hline Correlation & Significant Value \\
\hline$-.575^{* *}$ & .000 \\
\hline$-.406^{*}$ & .017 \\
\hline $.800^{* *}$ & .000 \\
\hline $.452^{* *}$ & .007 \\
\hline
\end{tabular}




\subsection{The Familiarity of Indonesian Girls towards Rights to Educa- tion}

A question about awareness to rights to education was sent to 100 girls randomly via surveymonkey.com. The survey data (image 2 ) indicated that almost three-quarters (73\%) of participants in this study are not aware of rights to education at all. The high number is of hug concern. Only $2 \%$ of all participants are extremely aware of rights to education.

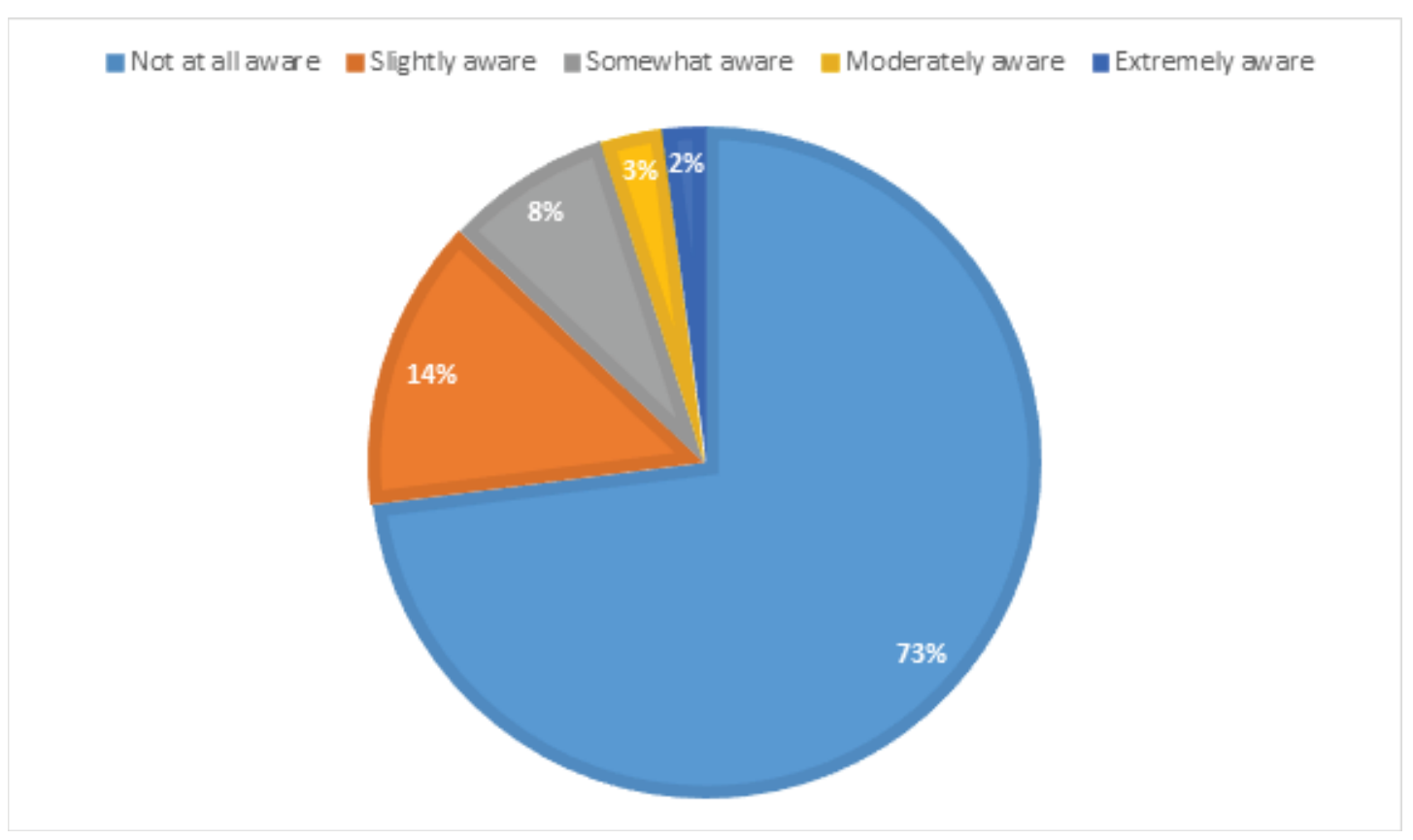

Figure 2: Awareness of Indonesian Girls towards rights to education

\section{Discussion and Recommendation}

Discrimination in girl's education frequently happens in almost all countries in the world, especially in developing countries. There are several factors that can influence this issue happening, yet in this study, the family income is the only factor which is investigated. Based on the result (image 1), family with lowest income seems to lag far from the knowledge of equality in children's education. This case can be categorized as an offence of article 2 which refers to non-discriminatory provision. The culture may be indicated as the reason why parents tend to send their sons to school rather than their daughter. Notably, the view on girls' education in Indonesia was impacted by history when the colonisation era degraded the dignity of woman (Prasilowati, 2000). 
In this survey more than half of the participants about awareness of rights to education acknowledged that they are not aware at all about the rights. Education frames the civilisation, thus unawareness of the rights to education can be a solemn obstacle to human development. Thus, to cope that all children have to know that they have the right and they have to respect others (Verhellen, 1993). The implication is that when they grow to become parents they must know how to decide the education for their children and respect it. In this case, the highest schooling level for Indonesian girls is secondary school. Therefore, HDI is strongly related with this. In fact, with the last HDI, Indonesia still lags far from achieving the status as developed country - prompting the girls to pursue higher education can change the status. So, the decision of parents towards education of their children indirectly is affected by their knowledge in education's rights itself and globally it will impact on the society.

Although in Indonesia the lesson about rights and law is taught in the subject 'civilisation' from primary to higher education, teaching knowledge about rights to education is not enforced. So, the further curriculum especially in civilisation education should recognise the importance of teaching children's rights to education. Consequently, there will be more people, especially female, who will be aware of rights to education. Moreover, the governments should pay more attention to the children's education in families of low income. They have to promote equality in children's education between girls and boys in order to increase the dignity of the whole nation without any exception or discrimination.

\section{References}

[1] Ball, S. J. (Ed.). (2013). Foucault and education: Disciplines and knowledge. Routledge: London.

[2] Daimaria, P. (1996). Women and Culture in Indonesia: Images in Religion, Customary Law in the State. Lila-Asia Pacific Women's Studies Journal, vol. 6, pp. 7-11.

[3] Hart, S. N. (1991). From Property to Person Status: Historical Perspective on Children's Rights. American Psychologist, vol. 46, no. 1, p. 53.

[4] King, E. M., \& Hill, M. A. (Eds.). (1997). Women's education in developing countries: Barriers, benefits, and policies. World Bank Publications. Baltimore, MD :The Johns Hopkins University Press.

[5] McCracken, K., et al. (2015). Empowering Women and Girls through Education. Brussels: European Parliament.

[6] McGivney, V. (1993). Women, Education and Training. Guildford: NIACE. 
[7] Moose, J. C. (1993). Half the world, half a chance: an introduction to gender and development. Oxfam. Oxford: Alden Press.

[8] Noorbakhsh, F. (1998). A Modified Human Development Index. World Development, vol. 26 , no. 3 , pp. 517-528.

[9] Paechter, C. (1998). Educationg the Other: Gender, Power, and Schooling. London: Falmer Press.

[10] Prasilowati, S. (2000). An Analysis of Women's Education in Indonesia: Empowerment and Barriers. Halifax: Saint Mary's University.

[11] Riddell, S. (1992). Gender and Education: Progressive and Conservative Forces in the Balance. Scottish Council for Research in Education, vol. 12, pp. 44-53.

[12] Rose, P., \& Subrahmanian, R. (2005). Evaluation of DFID Development Assistance: Gender Equality and Women's Empowerment: Phase II Thematic Evaluation: Education. Department for International Development, London.

[13] Scott, J. (2004). Family, Gender, and Educational Attainment in Britain: A Longitudinal Study. Journal of Comparative Family Studies, pp. 565-589.

[14] Spring, J. (2000). The Universal Rights in Education: Justification, Definition, and Guidelines. New York: Routledge.

[15] Verhellen, E. (1993). Children's Rights and Education: A Three-Track Legally Binding Imperative. School Psychology International, vol. 14, no. 3, pp. 199-208. 